Advances in Intelligent Systems and Computing 970

Richard H. M. Goossens Atsuo Murata Editors

Advances in Social and Occupational Ergonomics

Proceedings of the AHFE 2019 International Conference on Social and Occupational Ergonomics, July 24-28, 2019, Washington D.C., USA 


\title{
The Common-Sense Assessment of Sustainability
}

\author{
David Camocho $^{1,2,3(\bowtie)}$, José Vicente ${ }^{2}$, and Ana Margarida Ferreira ${ }^{1,2}$ \\ ${ }^{1}$ IADE, Universidade Europeia, Av. D. Carlos I, 4, 1200-649 Lisbon, Portugal \\ david.camocho@gmail.com, \\ ana.margarida.ferreira@universidadeeuropeia.pt \\ 2 UNIDCOM/IADE - Unidade de Investigação em Design e Comunicação, \\ Av. D. Carlos I, 4, 1200-649 Lisbon, Portugal \\ jmanvicente@gmail.com \\ 3 Laboratório Nacional de Energia e Geologia, I.P., \\ Estrada do Paço do Lumiar 22, 1649-038 Lisbon, Portugal
}

\begin{abstract}
Products claiming sustainability benefits have been spreading all over the world in response, manly, to the consumer's behavior change towards a healthier and more sustainable way of life.

However, what guarantee do consumers have that the products they are consuming are in fact more sustainable? Apart from certified products, the consumer believes in a common-sense assessment of sustainability supported in part by self-declarations and allegations from designers, producers, and retailers focusing only in few aspects of the life cycle, and in some cases, misleading consumers through greenwashing approaches.

This paper is part of a Ph.D. research aiming to support a transition to circular economy and sustainability through design. The authors explore in this article the consumer perceptions of sustainability in products and communication strategies adopted. The results will support the development of guidelines to promote a more effective design practice for the development of sustainable and circular economy-based products.
\end{abstract}

Keywords: Design $\cdot$ Circular economy $\cdot$ Consumer perception $\cdot$ Common-sense assessment $\cdot$ Sustainability assessment $\cdot$ Sustainability

\section{Introduction}

The paper presents the research under development which aims to help the transition to a more sustainable and circular economy through design. The authors believe that design practice has a crucial role in defining the characteristic of the products and services that fulfill the needs of society. Also, that their impacts in the life cycle are defined in the design and development phase. In order to promote design and the practice of design, it is important to understand how eco and sustainable products and services are developed and placed on the market, how they communicate to users their 